\title{
A RITMANÁLISE DA EDUCAÇÃO: A IMAGEM DA CRIANÇA EM BACHELARD
}

\author{
Gabriel Kafure da Rocha ${ }^{1}$
}

RESUMO: $O$ presente artigo pretende tratar a função metodológica da ritmanálise como caminho para ir além na capacidade criativa de produzir e transmitir o conhecimento. Para isso, utilizaremos de Gaston Bachelard sua a imagem primordial da criança no desvelamento do instante e da problematização da intuição. Com isso, abordaremos o diálogo entre obras como A filosofia do não (1974), A intuição do instante (2007) e A Dialética da Duração (1994).

PALAVRAS-CHAVE: Bachelard; Infância; Instante; Duração; Ritmo.

ABSTRACT: This article aims to address the methodological function of ritmanálise as a way to go beyond in the creativity capacity to produce and transmit knowledge. To achieve this objective, Bachelard's primordial image of the child in the unveiling of the moment and the problematics of intuition. With that, we will cover the dialogue between Works as The philosophy of no, The intuition of the instant and The Dialectic of Duration. 
A RITMANÁLISE DA EDUCAÇÃO: A IMAGEM DA CRIANÇA EM BACHELARD

KEYWORDS: Bachelard; Childhood; Instant; Duration; Rythm. 


\section{CONSIDERAÇÕES INICIAIS}

Se fizéssemos isso, haveria uma pedagogia do tempo, uma pedagogia da educação. [...] o ritmo da escola é um ritmo que não é estudado. Nós não fazemos os programas passando pela psicologia, e não vimos, especificamente, [...] a atividade vibratória da criança. (BACHELARD, 1937, p. 30).

O presente artigo consiste numa aproximação ao pensamento de Gaston Bachelard (1884-1962) junto à proposta da ritmánalise ou ritmo-análise empreendida pelo filósofo, ideia que, colocada em certo momento de sua obra, consistiu em um ponto de intersecção entre os conceitos temporais de duração e instante ${ }^{2}$. Por esse motivo, é possível dizer que tal categorização pode ser considerada como método na estratégia de formação e deformação de imagens em ritmos. Nesse caminho, será necessário primeiro desdobrar a questão do tempo como duração, que consiste não somente como um obstáculo epistemológico ${ }^{3}$, mas também como um erro propedêutico, diante dos fatos que delinearão o ensino das ciências, em geral, e diante da imagem entre criança-adulto, professor-aprendiz.

Bachelard entende que não existe somente uma forma de se apresentar a racionalidade do real, para ele, a realidade é um conjunto de confrontos e contradições que por sua vez, no curso da história, se dão como rupturas, ou seja, elas não duram, mas se apresentam num instante como verdade e atomização do tempo. O instante seria como o prisma da noção da descontinuidade, de modo que é nessa 
atomização que está a chave da unidade do conhecimento como uma realidade "entre dois nadas", ou seja, tomando o nada como uma ideia da clareza que possibilita o início, valor e intensidade da instância presente.

Assim, ao adentrar no instante como possibilidade e intensidade da formação do conhecimento, a presente investigação começa então com a seguinte hipótese dentro do processo da propedêutica da aprendizagem: se, para Bachelard, os piores alunos são os melhores cientistas, é possível contemplar também que os melhores professores podem ter sido então os piores alunos ${ }^{4}$. O juízo de valor que a sociedade traça perante a educação acaba por ser abarcado na filosofia bachelardiana como uma relação entre a ciência e o ensino, de modo que é preciso estar atento à premissa ligada principalmente ao erro. Visto que o posicionamento diante dele precisa superar a sua representação enquanto obstáculo a ser descartado, para então desconstruir a imagem própria do erro em direção a uma dimensão em que nele está um dos aspectos mais valiosos do processo do conhecimento.

Urge então esclarecer primeiramente a questão: qual é a imagem que Bachelard desenha sobre o professor e o aluno e o que há de obstáculos e/ou rupturas entre tais? Primeiramente, o professor pode ser visto como o facilitador do incentivo ao aluno pelas perguntas do conhecimento. O professor/filósofo deverá sempre se renovar com suas formas de perguntar e questionar, ele deve mostrar ao aluno qual é a melhor forma de entender e delinear a pergunta na busca pela qual o aluno encontre seu motivo inventivo à pesquisa. $O$ professor nega a 
aparência das convicções rápidas e funda a incerteza como estratégia de aproximação da realidade, essa, pelo menos, é uma das interpretações possíveis da relação educação e ciência presentes justamente na Filosofia do não (1974).

Para ensinar o aluno a inventar, o professor deve primeiramente mostrar-lhe a capacidade de descobrir o que já foi descoberto. Reconstruir o que já foi inventado e, depois, dialeticamente negar o conhecimento prévio para inventar o novo.

No caminho da dualidade ciência-poesia, natureza e artificialidade, a característica fundamental dos binômios conceituais é a sua complementariedade. A unidade dessa oposição tem como ponto de encontro o ritmo, que em suas pontuações e instantes, aproximam ou distanciam esses binômios da própria relação professor-aluno, ensino (ciência) e aprendizagem (poética, ou melhor, estética, visto que é instante em que deve se iniciar o gosto pelo conhecimento).

Tal relação abre espaço para uma discussão que gira em torno da relação da metafísica no processo intuitivo em que o erro e a retificação são fundamentais para a manutenção e inovação da dualidade do conhecimento.

Em um primeiro eixo, no qual a perspectiva da intuição da infância, aliada ao psiquismo do instante e da epistemologia do erro pode revelar uma nova perspectiva de uma ontologia propedêutica em Bachelard, demonstra que o ritmo do aprendiz-professor é metabólico e educativo na medida que a sua própria imagem da criança é um desdobramento da sua formação quando adulto. Logo, o gosto pelo conhecimento deve ser fundamento e 
estimulado diante das delineações mais pedagógicas ${ }^{5}$, o que geraria uma grande reflexão sobre várias características da história da educação e como podem ter tido consequências erradas ou pelo menos em desacordo com suas próprias teorias.

Levando em conta que os próprios erros se configuram numa valorização de novas possibilidades do processo educativo, o segundo eixo que nos debruçaremos na presente investigação, no qual a metafísica tem uma influência na noção de intuição como duração, nos leva a algo mais problemático. $\mathrm{Na}$ fase diurna, Bachelard tece várias críticas à noção de intuição como obstáculo epistemológico, contudo, a partir da Dialética da duração $(1994)^{6}$, começa a ocorrer uma virada nessa noção. A obra, apesar de pender ainda para o lado mais diurno do filósofo, acaba por ser, junto com a Intuição do instante (2007), uma das obras que emergem a noção de descontinuidade ${ }^{7}$. Logo, a própria intuição atende uma descontinuidade, posto que se a duração só pode ser apreendida intuitivamente, a descontinuidade do instante passa então a relação intuitiva do que é sentido (duração) e observado temporalidade.

Pode afirmar-se desta que é uma análise de fenómenos rítmicos às escalas da matéria (desde a radiação), da vida e do espírito, consoante o conceito criado pelo filósofo bracarense Lúcio Alberto Pinheiro dos Santos (1889-1950) e divulgado por Gaston Bachelard em La Dialectique de la Durée (1936). Mas esta definição deverá parecer insuficiente à luz de uma interpretação magnificatória que mostre, por um lado, que a 
ritmanálise é uma filosofia criacionista do movimento rítmico universal e por outro, que ela corresponde a um novo paradigma de conhecimento. (CUNHA, 2008, p. 165)

O que Rodrigo Cunha pretende é estabelecer a gênese do conceito de ritmanálise em Portugal, esclarecendo que antes de Bachelard, já havia um profundo diálogo entre dois filósofos portugueses, Leonardo Coimbra e Lúcio Pinheiro dos Santos, contudo, essa questão não é o objetivo do presente artigo. É interessante que nessa linha de pensamento, Bachelard realiza uma ontogênese do ser e do indivíduo na perspectiva da ritmanálise. Nesse sentido, pretendemos introduzir, com essa ontogênese do instante, um paradigma para a temporalidade perante ao conhecimento realizado pela criança.

\section{A PROPEDÊUTICA DO RITMO}

No período em que Bachelard escreve A dialética da duração, momento das obras em que se evidencia uma chamada "tentação bergsoniana", é dito que o resultado dos estudos que aliavam a Intuição do Instante e da Dialética da Duração se constituíram numa "dialética autógena" que tenta equilibrar o bergsonismo entre as polaridades da continuidade e descontinuidade. A dita propedêutica dessa fase, no âmbito dessa tendência, foi o germe de uma epistemologia que subjaz tanto ao poeta quanto a ciência. Logo, por algum motivo era preciso uma forma de 
psicologia que fizesse voltar a pré-condição da filosofia, e essa devia ser sempre a motivação das zonas do instante.

O que é fundamental na crítica ao impulso da continuidade bergsoniana é que ela impediu a ideia do nada, a dita primeira ideia clara que emerge da metafísica. Segundo Gagey, em seu livro sobre a conversão do imaginário, "O saber do tempo não é devido à pobreza desta intuição que dura, ou a memória de um tempo passado e armazenado." Esse saber em questão, dentro da perspectiva do esclarecimento da ciência do tempo como instante, é a constatação do nada justamente como a evidência de que tudo precisa ser construído a todo momento.

A questão do instante, para Bachelard, é o próprio problema da intuição da duração. O filósofo coloca-se de um ponto de vista diferente da intuição do cogito, pois, por meio do instante é possível adentrar nos vazios da história como totalidade e com isso retirar desses vazios algo novo. A intuição, de fato, é uma fonte de acesso a esses conhecimentos e o instante é a realidade da intensidade que se preenche e se esvazia da contraposição das realidades dessa totalidade. Ele, o instante, é o átomo do tempo. ${ }^{8}$

Ritmo e palavra fazem vivenciar a intuição da realidade e a única realidade temporal é o instante suspenso por nadas (o nada do passado e o nada do futuro entre o eterno e presente agora). É daí que surge a onda rítmica do universo, das deformações que o instante provoca no espaço-tempo como ondas rítmicas. Meditar sobre a presença só acontece no instante e dele, com suas multiplicidades, surge a memória, como a repetição do instante ou da órbita da rotina. Daí que a própria criança irrompe sua cognição, posto que até certa 
fase, a criança só tem a memória do que é mais próximo dela e ainda assim precisa de uma fase de repetições para que se habitue e memorize certas imagens e acontecimentos.

O instante como ruptura do ser se faz necessário nesse processo construtivo da memória, pois é disso que irrompe as novidades propedêuticas, fruto muitas vezes dos próprios aprendizados dolorosos. Os momentos em que a criança teve suas primeiras quedas ao aprender a andar são marcos da memória, em que as palavras antes e depois começam a fazer sentido a partir dos pontos de referência. Tais pontos que se não tiverem dimensão são como instantes sem duração que nos levam a noção do tempo.

É interessante lembrar como o tempo e espaço se dispõe em dimensões, que na física, "os autores afirmam que o tempo compartilha com o espaço a propriedade de ser um 'lugar' (aspecto da segunda dimensão do espaço ontológico), porém tem uma natureza mais 'dinâmica' (primeira dimensão). Apresenta as características de 'causa' (quarta dimensão), sendo uma espécie de 'lugar que pode efetuar mudanças)'. [Isto é,] ao mesmo tempo discreto e contínuo (terceira dimensão). (MARTINS, 2004, p. 100)

É a dimensão da experimentação dos atos como continuidade, que dá a tentativa de conexão entre o ritmo do nosso ser e do cosmos encontrando uma sincronia dos fenômenos, que podem nos levar até mesmo além das dimensões contínuas. É como um ajustamento entre o devir e a ação do indivíduo que faz com que a criança se aproprie e domine seus movimentos num instante atemporal, pois 
nela ainda não há consciência da memória subjetiva. Essa é justamente a possibilidade uma ontologia da percepção de si, do próprio conhecimento que se desenvolve a partir da consciência do vir-à-ser da criança como conhecimento dela mesma ao se tornar um indivíduo.

Entendendo que as construções dessas noções substituem a duração pela ideia da memória do ritmo, essa é a descrição da energia do crescimento do universo dentro da criança. Por esse processo, a criança vai expandindo seu mundo dentro de um universo como um todo, ela vai se apercebendo de que o mundo não gira ao redor de si, mas da complexidade de como as pessoas se tornam eixos umas das outras.

A melhor metáfora que Bachelard utiliza para essa descoberta é a música, isto é, o hábito da noção de continuidade. Ele demonstra, contudo, numa imagem harmônica que é pela ruptura do arco contra o violino que se desenvolve o som. Da mesma maneira que os hábitos de um músico demonstram como a clareza de captar a essência de uma síntese se dá nos instantes, ainda sobre esse hábito, no geral, o seu caráter "está inscrito no ser. A nosso ver, seria melhor dizer, empregando a linguagem dos geômetras, que o hábito está exscristo ao ser". (BACHELARD, 2007, p. 69)

A exscrição dos hábitos seria uma oposição ao realismo abstrato na medida em que a complexidade deles correspondesse a simultaneidade de sensações como qualidade, harmonia e ritmo. Por isso, nessa medida, a matéria é um próprio hábito do ser que quando sustenta um ritmo, no ato da repetição do instante, isso é visto 
como um ato psicológico ou o hábito-ritmo. "Bachelard vai mostrar que a duração nada mais é do que uma reconstrução psicológica que nasce da repetição de ritmos. O ritmo é que dá a continuidade da duração, pois o passado é um hábito presente, e o futuro, um ritmo antecipado". (BULCÃO, 2009, p. 187)

O entendimento do indivíduo como soma de acidentes ou instantes, ou mesmo de ultrapassagem de obstáculos que o fazem vir-a-ser, é a constatação de que o ser é velar e desvelar na medida em que é ele mesmo descontínuo. Há uma profundidade meta-imagética, metalinguística da realidade do instante como uma espécie de ser espelho do espelho, reflexo do reflexo. "A concepção do indivíduo como somatório integral dos ritmos é, talvez, suscetível de uma interpretação cada vez menos substancialista, cada vez mais longe da matéria e mais perto do pensamento". (BACHELARD, 2007, p. 73). Nessa proximidade ou distanciamento da matéria para o pensamento, o hábito se representa na ideia do progresso, no entanto, isso se contrapõe também ao grau técnico de progresso científico e mesmo propedêutico que estamos buscando nessa investigação. Então, enquanto o instante adiciona a novidade temporal ao progresso, essa renovação é uma reinvenção em que interagem interior e exterior, aqui e agora, numa reinvenção dos horizontes do mundo.

"Subitamente, a achatada horizontalidade, e o tempo deixa de correr, passando a jorrar como a eterna fonte da juventude de Silöe”. (BULCÃO, 2009, p. 192). É importante ressaltar que duração, hábito e o próprio ritmo são 
fenômenos que decorrem do instante e a importância que esses fenômenos revelam, se deu a partir da leitura de Bachelard da obra Siloë de Gaston Roupnel (18711946), vista como uma chave da compreensão do universo mítico e até o científico demonstram como essa teorização tem um peso e um valor muito grande para a filosofia bachelardiana. Contudo, essa compreensão exige um processo de desconstrução da realidade extremamente árduo, que é paradoxalmente natural na criança e no poeta.

A poesia que mais se aproxima do que pode se concretizar como unidade do ser e do objeto é que "o poeta é, então, o guia natural do metafísico que quer compreender todas as potências de ligações instantâneas, o ímpeto do sacrifício, sem se deixar dividir pela dualidade filosófica grosseira do sujeito e do objeto". (BACHELARD, 2007, p. 107)

\section{A POÉTICA E OS OBSTÁCULOS NA INFÂNCIA}

"A infância é fonte de nossos ritmos. É na infância que os ritmos são criadores e formadores. É preciso ritmanalisar o adulto para devolvê-lo à disciplina da atividade rítmica à qual ele deve o florescimento de sua juventude". (BACHELARD, 1994, p. 134). Para falar da infância em Bachelard, é essencial compreender que ela dura a vida inteira, ou seja, ela tem sim uma efetividade de uma duração instantânea que anima o desencanto da vida adulta. Nisso se mostra que a criança que fomos é a chave para a criação de conceitos e devaneios. A 
infância, em termos propedêuticos, tem como característica uma indução, pois tudo o que a criança aprende é fazendo, ela investiga o mundo de uma maneira essencialmente científica.

Ser criança é poder ser tudo, pintor, escultor, caçador, músico, médico, etc. A maneira como a criança forma e deforma sua visão da matéria aponta que os jogos infantis de ficção e construção, de armazenamento das imagens serão fundamentais para as atividades que irá exercer quando adulto. A criança consegue ver o que o adulto já perdeu de vista, por isso é um desafio para o adulto resgatar e ressignificar a criança que há em si. Significa tirar a univocidade de sentidos que a realidade tende a substancializar na mente dos adultos. Esse processo é fundamental na medida em que o encanto pela novidade, pelas primeiras cores ${ }^{9}$ guardadas na memória que podem voltar a renascer no adulto.

A memória funciona como animus, face da consciência que revela a história, já a imaginação é representado pelo animus, face da consciência que revela os valores íntimos do ser. Ora, essa complementariedade entre memória e imaginação, animus é o que dá sentido a dialética de Bachelard como relação entre o grande e pequeno, horizontal e vertical, de dentro e de fora ou mesmo da criança e do adulto. A disposição em que as crianças vivem entre o mundo real e o imaginário, por serem espontaneamente curiosas e críticas do mundo, lhes faz descabidas de preconceitos, ora, o que num sentido fenomenológico, para Bachelard, é que a criança é a própria imagem da miniatura. ${ }^{10}$

De tal modo que, para a criança, o fascínio pelo grande vai dando lugar ao adulto com o fascínio pelo pequeno. Nota-se, por exemplo, que um grande urso de pelúcia toma lugar do 
valor do fantástico por uma pérola, por exemplo, para alguém na fase adulta. É aqui que é importante ressaltar que Bachelard não quer uma visão da criança como miniatura do adulto. É o que na tese de André Martins, entra em questão justamente no ponto em que o tempo intuitivo, das ações da própria criança evoluem numa direção da homogeneidade. É aí que as análises da infância, nos experimentos de Piaget, mostram como as perspectivas dos movimentos e velocidades do tempo como objeto-tempo físico e sujeito-tempo psicológico descentram a intuição.

Talvez seja essa deformação da intuição que Bachelard quisesse empreender ao criticar a intuição bergsoniana e que

Piaget analisa [como] o 'tempo vivido'[...]. Em oposição à hipótese de uma 'intuição imediata do tempo', Piaget procura mostrar como a constituição de um tempo psicológico também passa por uma coordenação de movimentos, mas agora de movimentos do sujeito, e não de objetos do mundo exterior. (MARTINS, 2004, p. 94)

Haveria de ser visto, então, num segmento da presente reflexão, em que medida Piaget corrobora ou rompe com a própria noção de Bergson. É possível afirmar que realmente Piaget teve uma influência bergsoniana, como o próprio Bachelard teve também e a tomou como perspectiva de embate. Contudo, o essencial desse contexto é perceber que em comum à propedêutica do ritmo em Bachelard, há que se convir, que há uma adequação com a teoria piagetiana. Logo, da mesma maneira que há uma evolução da ideia do tempo intuitivo por meio dos conceitos comuns de obstáculos e conquistas, assim também há a importância que 
Piaget, assim como Bachelard antes dele, teria usado o conceito de obstáculo através do termo representação. Mas no caso de Piaget, havia a intenção de descrever as concepções errôneas das crianças. (EICHLER, 2014, p. 77)

Há com isso, em alguns estudos, uma aproximação bem consolidada no campo pedagógico entre ambos os pensadores, tentando demonstrar a espontaneidade da racionalidade infantil, assim como também uma certa noção de obstáculos. No entanto, para Piaget, os obstáculos eram vistos como algo negativo e por Bachelard como essencialmente positivos e necessários. Isso se deu talvez porque Piaget considerou a possibilidade de obstáculos gerarem um conflito cognitivo, já para Bachelard, os obstáculos acompanham o desenvolvimento da criança até o adulto eternamente pelas rupturas das próprias fases do crescimento de um indivíduo.

\section{A QUESTÃO DO NÃO}

Se uma das primeiras coisas que as crianças aprendem a dizer é o não, então isso é fruto da socialização cognitiva da própria sociedade. A criança representa de certa forma, o espírito précientífico, na medida em que o erro nele se desvela nelas a partir de suas próprias negações. Ou seja, essa tendência pelo não, caso seja negada, torna-se a própria negação do erro do espírito científico da sociedade em relação à educação das crianças. Algumas tendências pedagógicas querem afirmar que é melhor evitar o próprio ensino do 'não' para a criança, mas de fato, 
ontologicamente, a dualidade entre sim e não é inseparável. A aceitação do não é uma espécie de fundamentação para superação de obstáculos. Ora, essa é a primeira dialética do conhecimento do mestre e do aprendiz na medida em que o aprendiz aprende a dizer não ao próprio mestre, quando ele é capaz de ter o espírito crítico da construção do seu próprio conhecimento. "Bachelard vai ressaltar que o erro tem uma função positiva na gênese do saber, e é exatamente isso que explica a dialética que caracteriza o pensamento científico da atualidade". (BULCÃO, 2009, p. 198).

Uma reflexão que se desvela da proposta bachelardiana é uma recorrência ao que vai se desvelando na materialidade dos os fenômenos da ciência, assim como eles vão sendo descobertos pela curiosidade do pesquisador, o ânimo que parte da sua interioridade é justamente o sentimento curioso infantil. Ora, é o encantamento desses fenômenos que em um momento dizem não a opinião da infância eterna.

Quando Bachelard fez a referência à psicanálise em $L a$ dialetique de la durée, não estava especialmente atento à obra de Freud. O seu interesse em nessa altura, residia nos trabalhos de um filósofo português Lúcio Pinheiro dos Santos que terá escrito o livro La rythmanalyse, onde se opõe Leonardo da Vinci ao contrapor a criatividade deste gênio, não a uma visão do passado traumático, mas a uma 'infância eterna' que seria tida como a fonte dos ritmos criadores no adulto. (GASPAR, 2010, p. 70)

Logo, para Bachelard, a maneira como a criança conhece os fenômenos é um desapego da ação mesma do fazer. Toda a indução da criança é interação entre observação (instante) 
e sentimento (duração). A multiplicidade criativa da criança mostra a natureza plural do conhecimento, assim como os primeiros cientistas tinham uma polivalência de conhecimentos (Leonardo Da Vinci, por exemplo, era pintor, escultor, engenheiro, etc). Todos nós, quando "crianças, éramos pintor, modelador, botânico, escultor, arquiteto, caçador, explorador. E o que aconteceu com tudo isso?" (BACHELARD, 1994, p. 76)

Esse conhecimento indutivo que inventa, destrói e reconstrói é justamente o tornar-se do processo, o devir do conhecimento pelos diferentes esforços de dor e de prazer na criança ou mesmo no adulto. Só que a maneira como a criança começava a lidar com a informação e deformar a realidade ludicamente nos faz questionar, o que leva ao esquecimento que obstaculizaria tudo isso?

Aí que entra o papel do professor, esse cientista que já foi criança e que por isso conhece e tem domínio dos gestos investigativos, é ele que, de maneira intuitiva, agora terá que sintetizar o seu momento pedagógico com a perspectiva criadora em que o aluno sinta-se encontrado na sala de aula, como um espaço íntimo da sua capacidade de criar. Nesse sentido, é lógico que se torna fácil entrar no discurso de que essa é uma bela teoria, mas que na prática a realidade da educação é muito mais complicada, visto que, no ideal da complexidade da teoria é preciso que o aluno tenha direito e acesso as ferramentas e técnicas de ponta, em laboratórios tenha um acesso livre. Contudo, sabe-se que isso está muito longe de acontecer por medidas burocráticas ou mesmo de segurança e preservação do patrimônio. 
Sem contar que a maioria das escolas sequer tem à disposição os aparatos técnicos que perfaçam a possibilidade dessa exercitação. Mesmo com isso, não se pode deixar esquecer que a representação do mundo comece a perder o sabor, na medida em que o apetite pelo conhecimento vai se perdendo é como a valor em um adulto em que as próprias cores do mundo vão se acinzentando. E o gosto pela ciência perde lugar pela religião ou televisão.

Ora, mas é aí que entra o aspecto peripatético originário e espacial do conhecimento. É aí que mora a esperança em que o professor, assim como o aluno, deve deixar literalmente a escola em nome da ciência. A pedagogia de Bachelard é vertical, pois seu eixo está situado no desejo de grandeza, na atualização da potência e da vontade. Por meio da simplicidade, ele, Bachelard (o professor-cientista-filósofo) convida a uma pedagogia do risco em encontrar o ritmo da felicidade na exterioridade. O pedagogo deve convidar os estudantes a se aventurar e não simplesmente ficar se insinuando como detentor de um saber hierárquico.

$\mathrm{Na}$ cidade científica ${ }^{11}$ é preciso dialetizar os conceitos, é preciso pensar filosoficamente a realidade. Quando se sai da escola, é preciso agrupar os conhecimentos e se perguntar sobre o que compõe a realidade exterior. Ora, qual é a história das ruas? Como é feita a matéria que cobre o chão? Como surgiram as indústrias que formam os produtos das lojas fora da escola? Enfim, não é possível dar a garantia do conhecimento, mas sim o dinamismo da sua complexidade interdisciplinar. O mestre que ajuda a questionar deve auxiliar também a interessar os alunos em como os problemas são colocados, ele deve justamente se ver como a criança na sede 
de conhecer tudo a sua volta. Menos do que resultados e soluções, o importante é a valorização do caminho.

Esse é um apontamento de um primeiro erro na pedagogia do crescimento humano, o processo de esquecimento da infância pelo gosto de certezas históricas que dogmatizam o pensamento. Contudo, isso tem a ver com a experiência de assumir a complexidade do mundo, de uma dualidade que vai além da razão e emoção, que vai além da objetivação e subjetivação. É preciso dizer não a decadência da própria educação e criar uma nova perspectiva a partir de métodos cada vez mais simples de compartilhamento de informações.

Nesse sentido, do mesmo modo que na infância a criança foi estimulada a ter coragem de encarar o desconhecido (ou seja, o mundo como o todo). Assim também, esse desconhecido, no campo da educação torna-se um necessário que se relaciona consigo mesmo. Dessa forma, ao desejar a mudança, este necessário não é mais 'ter' condições. Ora, não seria diferente, pois o necessário é inerente à sua natureza porque o necessário ' $\mathrm{E}$ ' no instante preciso do agora. O possível não se deixa predicar pelo necessário, já que reclama para si o porvir.

Claro que é preciso tomar cuidado com a necessidade do desconhecido, é preciso trabalhar desconfiadamente com a fenomenologia do campo do "não ser do que não é" (a consciência, de um ponto de vista sartreano) e a ambiguidade do devir que ela tem como sua natureza. É preciso lembrar-se de que o inconsciente é também necessário para a educação.

A pergunta bachelardiana sintetiza, então, a questão: como equilibrar o conhecimento imaginário com o pensamento 
pedagógico? Como não podar a capacidade imaginativa da criança? É preciso que as crianças e os jovens possam compreender a complexidade do mundo e ser capazes de contraporem-se às técnicas e tecnocracias. Em $A$ intuição do Instante, Bachelard vai caminhar pela chamada "pedagogia do descontinuo" em que a concepção de tempo como instante se dá todo momento no processo pedagógico.

A tentativa de homogeneidade é o primeiro erro denunciando por essa pedagogia em que se pensa que há uma continuidade entre a criança e o adulto. O que na verdade há, sim, é uma descontinuidade como a compreensão de um método de discursividade, como organização da diversidade dos pontos de vista, mas que há também agora continuidades da memória e da noção do ritmo.

Para Bachelard, a escola é uma demonstração do humanismo e do fato de que a única continuidade verdadeira do ser humano é a aprendizagem. Essa dinâmica exige que mestre e discípulo tenham a capacidade de inverter seus papéis. Seus pensamentos devem estar intimamente ligados na invenção de seus devires.

Em A poética do devaneio (1996) ${ }^{12}$, Bachelard relembra que o conhecimento devia ser uma virtude prática, ter uma finalidade, uma forma de trabalho crítico do seu próprio aspecto técnico. O trabalho é um valor primordial, ele sempre recomeça e se reconstitui, mutanti mutandis, o dinamismo do trabalho exige certa poética para lhe dar sentido. "Separado de seu ser para os homens, cria-se, sob a inspiração do mundo, um ser para o mundo. Eis o ser da infância cósmica." (BACHELARD, 1996, p. 100). 
O ser da duração que era entendida como substância anteriormente, mas que agora é o devir do fenômeno, nessa nova perspectiva, dessubstancializa-se como a duração da substância e observa-se em sua manifestação como novidade. A duração é o nada, um ataque sem repouso, o instante é o preenchimento da intensidade da potencialidade de aprender.

Para sair dessa dualidade, é preciso o salto, "Tudo ficará claro, por exemplo, se, para entrar no domínio em que se imagina, nos fizessem saltar no limiar do absurdo" (BACHELARD, 1974, p. 294). Esse salto que é uma das características próprias da descontinuidade, que proporciona o olhar vertical para o mundo em que estamos, agora pode observar o horizonte daquilo que pensávamos anteriormente, que agora pode ser desconstruído na ritmanálise do instante descontínuo do conhecimento criador, que salta no espaço-tempo e produz propedeuticamente o conhecimento novo.

\section{CONSIDERAÇÕES FINAIS}

O élan ritmanalítico seria tangível em alto grau na obra de Bachelard, não só na perspectiva epistemológica do modelo rítmico aplicado, como especialmente nos trabalhos em torno da "imaginação material" e da dialéctica do psiquismo, particularmente na versão ritmanalítica, de resto abrindo portas criacionistas às epistemologias contemporâneas. Uma ritmanálise da obra bachelardiana no seu conjunto, entre ciência e poética, encontra precisamente na expressão multímoda da experiência do ritmo, não uma convergência anfibológica, mas sim o pulsar de um novo paradigma sapiencial. (CUNHA, 2008, p. 167) 
A experiência estética de meditar sobre a descontinuidade do tempo, por meio da noção do ritmo e seus instantes, evidencia em suspensão o problema da composição não substancialista. A continuidade psíquica faz da vida uma obra, um hábito da síntese da descontinuidade mais rítmica. É a convergência da liberdade e necessidade por determinar a vibração da exterioridade. O ritmo é o poder de organização dessa grande desordem substancial e caótica que é a realidade. Ora, a ideia da substância é a separação absoluta entre espaço e tempo e isso tem que ser desconstruído.

Se o processo de crescimento e evolução da criança é justamente esse aprendizado de separação para a cognição do tempo da vida, então a 'Visão de mundo' (Weltanschauung) fenomenológica permite o retorno as noções mais intuitivas.

Por sua vez, tão encantado e irritado com o tempoduração ele [Bachelard] quer que dialétizar o conceito. Dar-se uma filosofia da infância feliz, para fundar outra forma na própria razão, o direito pensado para uma vida subjetiva, enquanto porque não basta oferecer um refúgio para os poderes secretos da alma, talvez seja impossível ganhar a aposta. (GAGEY, 1969, p. 80)

Desse modo, A Intuição do instante demonstra por fim uma serenidade e um repouso como um acordo transparente de encontro com a fonte da alma poética, essa base filosófica da afirmação de si e de sua criança interior, por toda a vida. Bachelard nos mostrou como sua noção de instante perpassa pelas querelas do surgimento das ideias da filosofia moderna, redimensionando e organizando a noção de hábito, ritmo e instante dentro de um direcionamento 
pedagógico e propedêutico da aceitação de diferentes formas de racionalidade, dedução, indução e educação do saber científico. Por sim, é sempre bom lembrar que "a ciência é a estética da inteligência", essa frase célebre da Formação do espírito científico que deve imprimir sempre ritmo a essa propedêutica criadora e produtora do conhecimento, desde a criança até $\mathrm{o}$ adulto.

\section{NOTAS}

${ }^{1}$ Doutorando em Filosofia pela UFRN e Professor do Instituto Federal do Sertão Pernambucano. E-mail: gkafure@gmail.com.

${ }^{2}$ Para a análise desses conceitos, nos utilizamos dos livros $A$ intuição do Instante (publicada originalmente no ano 1933) e a Dialética da Duração (publicação original de 1936). São duas obras que dialogam entre si a respeito do conceito de tempo e da crítica ao bergsonismo da época.

${ }^{3}$ Esse é um conceito essencial na teoria de Bachelard. Apesar do conceito de obstáculo aparecer inicialmente em A formação do Espírito científico (publicada em 1938), utilizaremos aqui o delineamento conceitual utilizado em A filosofia do não, do ano de 1940.

${ }^{4}$ De fato, tal afirmação é feita aqui como uma paráfrase da paráfrase, visto que tal inspiração se deu devido à citação que diz "O físico Gaston Bachelard, no seu livro A Formação do Espírito Científico [...], diz-nos que 'os melhores alunos são os piores alunos' e 'os melhores alunos são os piores cientistas'”' (Marques, 2014, p. 40) no Livro A ecologia Humana no Brasil, organizado pelo Prof. Dr. Juracy Marques. Contudo, ao conferir A formação do espírito científico, não encontramos efetivamente lá tal citação. Uma citação que guarda alguma semelhança, mas evidentemente não quer dizer a mesma coisa, é a da célebre questão pedagógica que Bachelard proferiu em uma conferência de 1952 que diz: "Numa palavra, a escola é feita para a sociedade. Mas como tudo seria mais claro, mais agradável para o coração do homem, 
se, invertendo a proposição, disséssemos: a sociedade é feita para a Escola. A Escola é um fim." (BACHELARD, 1967. p. 34).

${ }^{5} \mathrm{~A}$ dimensão pedagógica que mais parece se afinar com a perspectiva bachelardiana é o construtivismo de Jean Piaget (1896-1980). Em uma das poucas referências que Bachelard faz à Piaget, encontramos, ainda no texto $A$ vocação científica e a alma humana, conferência já citada e proferida em 1952, a seguinte citação: "Perante uma criança que aprende, maravilhamo-nos com a sua maravilhosa surpresa. E, o que é menos sensível, surpreendemo-nos com a nossa inesperada capacidade pedagógica. Sabemos tanto, a criança sabe tão pouco, por isso que a súbita alegria nos invade ao ensiná-la! Justa ou injustamente muitas vezes injustamente, supomos ser capazes de nos pôr ao nível da criança. Na cidade onde Jean Piaget ministra o seu prestigioso ensino, desnecessário se torna insistir nessa comum satisfação que anima a criança interrogada e o psicólogo que a interrogou." (Bachelard. Ibid., p. 22 - grifos nossos).

${ }^{6}$ Podemos considerar, nesse sentido, que a própria incorporação da teoria de Lúcio Pinheiro dos Santos, de La rythmanalyse, publicado originalmente no prefácio e no VIII capítulo do texto bachelardiano La dialectique de la durée de 1933 foi uma intuição na perspectiva de desconstrução do sistema bergsoniano. Ora, quando Bachelard aceita todo o sistema de Bergson (18591941), mas abdica justamente da duração - o conceito pilar do seu sistema ele propõe justamente que as intuições são continuístas são também obstáculos do conhecimento, elas tem sua utilidade na dimensão noturna, mas no aspecto diurno devem aceitar a natureza da sua própria ruptura rítmica.

${ }^{7}$ Em Bachelard, existe a noção de descontinuidade temporal e descontinuidade científica, que ele também chama de ruptura epistemológica. Tomando o sentido de ambas descontinuidades como um principio filosófico a ser aplicado na educação, abordaremos mais à frente a descontinuidade epistemológica no sentido prático da essência do obstáculo, não é necessariamente a noção do obstáculo epistemológico de A formação do espírito científico, mas o entendimento essa noção em A filosofia do não que coloca o obstáculo como parte da estrutura do conhecimento como origem primeira da busca. "Bachelard ne leur a consacré que deux chapitres de La Philosophie du non, alors qu'il a écrite un livre entier sur les obstacules que entravent la connaissance du réel." (PARIENTE, 2001, p 30). 
${ }^{8}$ Vale ressaltar que a própria imagem do átomo, nas Intuições atomísticas (1975), mostra como Bachelard tinha uma representação de destruição e reconstrução entre os modelos de física clássica e quântica. Tal afirmação se presentifica no fato de que as Intuições atomísticas foi uma das primeiras obras epistemológicas de Bachelard. E mesmo nela, as intuições são também uma partícula de uma fenomenotécnica, na medida em que o átomo, por exemplo, foi uma intuição antiga, um fenômeno criado do nada ou pelo menos das observações empíricas que os gregos tinham da partícula indivisível que compunha uma realidade e que a partir de tal intuição formou-se toda uma própria ciência: a química. "En effet, une fois que l'intuition a pris son point de départ dans l'expérience, cette intuition peut se développer en se à la propre force de l'expérience." (BACHELARD, 1975. p. 10).

${ }^{9}$ Sob esse assunto, é interessante a leitura da tese de Noemi Favassa, na perspectiva da percepção das cores ser também um desenvolvimento humano, do preto e branco ao colorido, na tese referida, há uma frase significativa que relembra como para Bachelard as cores se tornam palavras na medida em que no caminho de uma cor à outra, se há uma interpretação de como se dão essas passagens, ocorre algo semelhante a passagem de uma ciência a outra, ou conforme a própria passagem processo de aprendizado, então "Apreender no processo do movimento criativo da passagem de uma cor a outra é estar no mais etéreo do fenômeno, é alcançar a tenuidade da linha divisória e imaginária 'entre' as cores, podemos dizer de certa forma, que é apreender o inapreensível no devir que só a imaginação dá acesso." (QUEIROZ, 2013. p. 93).

${ }^{10} \mathrm{Um}$ texto interessante de Bachelard, O mundo como capricho e miniatura. Eis que, nesse texto, a miniatura é oposta ao o mundo como resultado do capricho, fragmentado e direcionado a um objeto específico, o mundo que se põe como um outro que está diante de si, esse é o mundo da razão e da representação científica.

${ }^{11}$ Bachelard via que o lugar do conhecimento deve contar mais do que um agrupamento de pessoas, ele deve ser uma polis, uma ágora em que haja comunhão de pensamentos, principalmente do racionalismo aplicado aos domínios das teorias, das técnicas e da verificabilidade que confirme e ensine a normalizar a ciência. 
${ }^{12}$ Tal obra, com seu capítulo "Devaneio voltados para a infância”, geraria todo um novo artigo a respeito da poética e imaginário infantil. É curioso que em uma carta de 31 de Outubro de 1959 à Henri Bosco (amigo e escritor o qual dedicou o seu livro Terra e os devaneios da vontade), pouco antes de escrever tal livro, Bachelard disse: "Quand vous allez lire mon prochain livre vous verrez que l’enfance est um des pôles de mês rêveries. Ici jétais devant une engance héroïque. Je ne sais pourquoi je me tout entier aux enfances courageuses, aux enfances qui lutte[nt] contre la misére. Il y a là une croissance d'homme que me donne, em lisant, de l'énergie.. (BACHELARD in: MORZEWSKI [org.], 2013, p. 37).

\section{REFERÊNCIAS}

BACHELARD, Gaston. La continuité et la multiplicité temporelle. Bulletin de la Société française de philosophie. Paris, 1937.

BACHELARD, Gaston. A vocação científica e a alma humana. In: Bachelard \& Schrödinger \& Auger \& Santillane \& Durbale. O homem Perante a ciência: texto integral das conferências e dos debates dos Encontros Internacionais de Genebra. Tradução Mário Braga. Lisboa: Publicações Europa-América, 1967.

BACHELARD, Gaston. A Filosofia do não: ensaio de uma filosofia do novo espírito científico. Tradução Joaquim José Moura Ramos. In: Bachelard \& Schrödinger \& Auger \& Santillane \& Durbale. Col. Os Pensadores. São Paulo: Abril, 1974.

BACHELARD, Gaston. Intuitions atomistiques. Paris: Vrin, 1975. 
BACHELARD, Gaston. A dialética da duração. Tradução Marcelo Coelho. 2a ed. São Paulo: Ática, 1994.

BACHELARD, Gaston. A poética do devaneio. São Paulo: Martins Fontes, 1996.

BACHELARD, Gaston. A intuição do instante. Tradução Antônio de Padua Danesi. Campinas, SP: Verus Editora, 2007.

BULCÃO, Marly. O racionalismo da ciência contemporânea Introdução ao pensamento de Gaston Bachelard. Aparecida, SP: Idéias \& Letras, 2009.

CUNHA, Rodrigo. A Filosofia do Ritmo Portuguesa: da Monadologia Rítmica de Leonardo Coimbra a Lúcio Pinheiro dos Santos e a Ritmanálise. In: Philosophica. Lisboa: Serra d'Ossa Edições, 31, 2008, p. 161-191.

EICHLER, Marcelo. A recepção diacrônica da obra de Jean Piaget na didática das ciências francófona. Schéme - In: Rev. Eletrônica de Psicologia e Epistemologia Genéticas. Marília: V. 6, n. 2 - Ago-Dez/2014. p. 68-92.

GAGEY, Jacques. Gaston Bachelard ou la conversion a l'imaginaire. Paris: Editions Marcel Riviére. 1969.

GASPAR, Ana. Entre o conceito e a imagem - o lugar da psicanálise na obra de Gaston Bachelard. Lisboa: Coleção Thesis. 2010.

MARQUES, Juracy. Ecologias Humanas. Feira de Santana-BA. UEFS, 2014. 
MARTINS, André. Concepções de estudantes acerca do conceito de tempo: uma análise à luz da epistemologia de Gaston Bachelard. Tese de Doutorado em Educação. São Paulo: Usp, 2004.

MORZEWSKI (Org). Les Cahiers Henri Bosco: Correspondance Gaston Bachelard - Henri Bosco. Paris: Artois Presses Université, 2013.

PARIENTE, Jean-Claude. Le vocabulaire de Bachelard. Paris: Ellipses, 2001.

PIAGET, J. A Noção de Tempo na Criança. Rio de Janeiro: Record. S/d.

QUEIROZ, Noemi, A ontologia da cor na fenomenologia estética bachelardiana. Tese de Doutorado em Filosofia. Natal: UFRN, 2013. 